\title{
EVALUATION OF PHENOLIC COMPOUND AND ANTIOXIDANT CAPACITY OF TWO VARIETIES OF OATS (AVENA SATIVA L) : BRAN OATS AND WHOLE GRAIN (BLACK AND PREVISION OATS)
}

\author{
*Samira MEZIANI ${ }^{1}$, Noreddine MENADI ${ }^{1}$, Hayet Mehida ${ }^{2}$, Soheila OUGAD $^{2}$, Souad \\ SAIDANI ${ }^{2}$, Lahouaria LABGA ${ }^{2}$ \\ ${ }^{1}$ Faculty of Life Science and Nature. Laboratory of Biotoxicology. \\ DjillaliLiabes. Sidi-Bel-Abbes, Algeria, meziani_samira@yahoo.fr \\ ${ }^{2}$ Faculty of Life Science and Nature. Department of Biology. \\ Djillali Liabes University. Algeria \\ *Corresponding author \\ Received $13^{\text {th }}$ December 2020, accepted 30 ${ }^{\text {th }}$ March 2021
}

\begin{abstract}
The objective of our work is to study the composition of total polyphenols, flavonoids and the evaluation of the antioxidant power present in whole prevision oats, whole black oats and prevision oat bran and black oat bran. Oats are a whole grain cereal with the most beneficial nutritional value; its regular consumption would be particularly beneficial in reducing the risk of cardiovascular disease. Good source of soluble fiber (beta-glucans), oat bran is the husk of the oat grain, it has many medicinal properties since it is able to regulate the metabolism of carbohydrates in people with diabetes, to greatly lower blood cholesterol levels, to prevent colon cancer and to fight against constipation by capturing water and thus facilitating transit. Oat bran is also widely used in the diet for its appetite suppressant action. The results obtained show that the total polyphenols represent respectively values of $0.205 \pm 0.0131 \mathrm{mg}(E A G) / g$ and $0.17 \pm 0.014 \mathrm{lmg}(E A G) / \mathrm{g}$ for prevision whole oat and whole black oats, $0.203 \pm 0.005 \mathrm{mg}$ (EAG) / g, $0.216 \pm 0.0117 \mathrm{mg} /$ EAG for prevision oat bran and black oat bran. for flavonoids, whole oats prevision has a rate of $0.192 \pm 0.371$ $\mathrm{mg} E Q / \mathrm{g}, 0.093 \pm 0.006 \mathrm{mg} \mathrm{EQ} / \mathrm{g}$ for whole black oats, and $0.201 \pm 0.025 \mathrm{mg} E Q / \mathrm{g}$ for black oat bran and $0.071 \pm 0.020 \mathrm{mgEQ} / \mathrm{g}$ for the prevision oat bran. The results of the antioxidant power reveal that the black oat bran has a high antioxidant activity $(I C 50=2.95 \mathrm{mg} / \mathrm{ml})$ followerd by prevision oat bran $(I C 50=6.15 \mathrm{mg} / \mathrm{ml})$ Whole oats prevision $(I C 50=6.37 \mathrm{mg} / \mathrm{ml})$ and whole black oats $(I C 50=11 \mathrm{mg} / \mathrm{ml})$.
\end{abstract}

Keywords: Oat bran, whole oats, polyphenols, flavonoids, antioxydant activity

\section{Introduction}

The Poaceae play a role at the global level by producing the basis of valuable food, Historically, the fruits of various cereals (wheat, rye, corn, barley, oats, rice and millet) have been one of the most important sources of food human and animal, both as fodder and as a nutritious grain, in terms of quantity oats rank among the first food products, it is one of the most important cereal crops in the world [1]. In recent years, public attention has been particularly focused on the health and well-being of the inhabitants, through the consumption of a healthy diet rich in cereals. Oats are rich in protein, fat, starch and phenolic compounds concentrated in the peripheral layer of bran [2]. Oats (Avena sativa L.) is considered a nutritional food of interest due to its high fiber content. Consumption of oats is believed to have various health benefits such as hypocholesterolemic and anticancer properties, oats have also recently been considered suitable in the diet of 
celiac disease patients. Oat-based bread [3] is considered to be an important value in combination with functional proteins, $\beta$ glucan and phytochemicals such as linked glycerol [2], ester linked alkyl conjugates [4], may have beneficial effects on human health. There are also fat, vitamins and minerals present in a considerable quantity [5]. They are functional foods known to provide a beneficial effect on the health of the consumer, decrease the risk of various diseases, the valuable physiological and nutritional attributes of oats by $\beta$-glucans and other components of dietary fiber, rich in tocopherol. The level of a natural antioxidant has generated an increased demand for oats in human nutrition [6]. Oats differ from other grains in that they are generally eaten as a whole grain, including the bran, as a result, the antioxidant-rich part of the grain is retained, including the phenolic compounds, which in oats are mainly represented by phenolic acids and avenanthramides [7]. Oats have various health benefits, cholesterol-lowering and anticancer drugs, recommended for patients with celiac disease. Additionally, it could be added to certain food products such as bread, cookies, and baby food [8]. The proteins, fibers, minerals and phenolic compounds present in whole oatmeal of which $100 \mathrm{~g}$ have almost $20 \%$ protein and more than $50 \%$ of carbohydrates, $15 \%$ of a soluble fiber $[9,10]$.

The objective of the present study was to determine the specific natural compounds of oats, to compare the phytochemical content in particular of the total phenolic content (TPC) of this species and to investigate the antioxidant power between prediction oats and oats black. This will help to reflect and reiterate the nutritional benefits of oats for consumers and the Algerian market.

\section{Matherials and methods}

\subsection{Plant Material}

The objective of this experimental study is to evaluate the level of flavonoids and total polyphenols, and to investigate the antioxidant power between two varieties of oats (prevision oats and black oats). The plant material of this study includes two varieties of oats: Oats prevision provided by Technical institute of field crops (ITGC) of and Black oats provided by national center for the control and certification of seeds and plants (CNCC) of the West region of Algeria. The results are given in (Table 1).

\subsubsection{Sample Preparation Method}

Whole oats: to obtain whole oats, the oat varieties were crushed using an electric grinder and the mash obtained was stored in paper bags at room temperature, in a place dry and protected from moisture and light until use. $20 \mathrm{~g}$ of each sample is macerated in $100 \mathrm{ml}$ of $70 \%$ ethanol, after the sample is stirred for 24 hours. After stirring, the solutions were separated by filtration. then undergo evaporation using a rotary evaporator at $45^{\circ} \mathrm{C}$, which removes the solvent in vacuo. Finally, drying in the oven.

Oat bran: Oat bran is obtained after separating the bran from the grain manually.

Table 1

Characteristics of the varieties

\begin{tabular}{|c|l|}
\hline Varieties & \multicolumn{1}{|c|}{ Characteristics } \\
\hline \multirow{2}{*}{} & Origin : Sidi bel abbes \\
\cline { 2 - 2 } & Type : pure line \\
\cline { 2 - 2 } & Half spreed tillering, low \\
\cline { 2 - 2 } & glaucescnece, high \\
\cline { 2 - 2 } & thousand grain weight, high yield \\
\cline { 2 - 2 } & Origin : Tiaret \\
\cline { 2 - 2 } & Type : pure line \\
\cline { 2 - 3 } & Half spreed tillering, low \\
\cline { 2 - 3 } & glaucescnece, high \\
\cline { 2 - 3 } & thousand grain weight, high yield \\
\hline
\end{tabular}

Samira MEZIANI, Noreddine MENADI, Hayet Mehida, Soheila OUGAD, Souad SAIDANI, Lahouaria LABGA, Evaluation of phenolic compound and antioxidant capacity of two varieties of oats (Avena Sativa L): bran oats and whole grain (black and prevision oats), Food and Environment Safety, Volume XX, Issue 1-2021, pag. 61 - 67 


\subsection{Methods}

\subsubsection{The determination of total polyphénoles}

In whole oat and oat bran extracts of the two varieties studied is carried out according to the method of Folin Ciocalteu [11]. The reagent used consists of a mixture of phosphotungstic acid $\left(\mathrm{H}_{3} \mathrm{PW}_{12} \mathrm{O}_{40}\right)$ and phosphomolybdic acid $\left(\mathrm{H}_{3} \mathrm{PMo}_{12} \mathrm{O}_{4}\right)$ of yellow color. The principle of the method is based on the oxidation of phenolic compounds by this reagent, which results in the formation of a new complex of metal oxides of tungsten and molybdenum in blue color. The intensity of the coloring is proportional to the amount of polyphenols present in the plant extracts [12]. $200 \mu \mathrm{l}$ of each extract, $800 \mu \mathrm{l}$ of sodium carbonate solution $\left(\mathrm{Na}_{2} \mathrm{CO}_{3}\right)$ and $1 \mathrm{ml}$ of Folin-Ciocaltaeu reagent are added to a hemolysis tube, after shaking the tubes are incubated for 30 min. Reading this fact has an absorbance of $765 \mathrm{~nm}$ using a UV spectrophotometer (the level of polyphenols was expressed in microgram equivalent of gallic acid per milligram of dry extract (mg EAG/mg ES).

\subsubsection{Anti-free radical activity with DPPH}

The evaluation of the antioxidant power of the various extracts is carried out by the DPPH test which is considered as a relatively stable free radical, the principle of this method is based on the measurement of the scavenging of free radicals of DPPH (1,1-Diphenyl-2picrylhydrazyl purple in color). In the presence of so-called antioxidant molecules, DPPH is transformed into its reduced form (diphenyl picryl-hydrazine: yellow in color), which leads to a decrease in absorbance [14]. The discoloration of DPPH is directly proportional to the ability of bioactive molecules to reduce it. According to the protocol described by Sanchez-Moreno (1998) and Agrawal calibration was carried out in parallel under the same operating conditions using gallic acid.

\subsubsection{The determination of flavonoids}

The method for determining flavonoids is based on the ability of these compounds to form chromogenic complexes with aluminum chloride $\left(\mathrm{AlCl}_{3}\right)$ [13]. $400 \mu \mathrm{l}$ of the extract, $2 \mathrm{ml}$ of distilled water and $120 \mu \mathrm{l}$ of sodium nitrite $\left(\mathrm{NaNO}_{2}\right)$ are mixed in a hemolysis tube, after $5 \mathrm{~min} 120 \mu \mathrm{l}$ of aluminum chloride $(\mathrm{AlCl} 3)$ at $10 \%$ are added after $6 \min 800 \mu \mathrm{l}$ of sodium hydroxide $\mathrm{NaOH}$ at $4 \%$ are added, the volume is adjusted to $5 \mathrm{ml}$ with distilled water after stirring the mixture is incubated for 15 min protected from light the reading this fact has an absorbance of $510 \mathrm{~nm}$ using a spectrophotometer. The concentration of flavonoids is calculated by referring to a calibration curve obtained using quercitrin. The concentrations are expressed in mg quercitrin equivalent (mg Eq Q).

(2011). The DPPH solution is prepared by dissolving $4 \mathrm{mg}$ of this product in $100 \mathrm{ml}$ of methanol. $50 \mu \mathrm{l}$ of each methanolic solution of the extracts at different concentrations are added to $1.95 \mathrm{ml}$ of DPPH solution. The mixture is left in the dark for $30 \mathrm{~min}$ and the absorbance reading is taken against a blank at $517 \mathrm{~nm}$ [15].

\section{Statistical analysis}

All results were performed in three replicates. The results are expressed as average \pm standard deviation. The data (the averages plus at least standard deviation as well as representations) are statistically analyzed using the statistical software EXCEL 2010.

Samira MEZIANI, Noreddine MENADI, Hayet Mehida, Soheila OUGAD, Souad SAIDANI, Lahouaria LABGA, Evaluation of phenolic compound and antioxidant capacity of two varieties of oats (Avena Sativa L): bran oats and whole grain (black and prevision oats), Food and Environment Safety, Volume XX, Issue 1 - 2021, pag. 61 - 67 


\section{Results and discussion}

\subsection{Dry extract yield}

The extraction yield is calculated by the following formula (Falleh et al, 2008).

$R(\%)=(M$ ext/M samp $) \times 100$

$\mathrm{R}:$ is the yield in \%

$\mathrm{M}$ ext : is the mass of the extract after evaporation of the solvent in $\mathrm{mg}$.

M samp : is the dry mass of the plant sample in $\mathrm{mg}$.

The yield of dry extract is calculated by adding $20 \mathrm{~g}$ of whole oats and $10 \mathrm{~g}$ of oat bran .

\subsection{Result of total phenolic content and flavonoid}

The total polyphenolic content of each extract was calculated from the calibration curve

$\mathrm{y}=8.721 \mathrm{x}-0.002$, where $\mathrm{y}$ is the absorbance and $\mathrm{x}$ the concentration expressed in milligrams gallic acid equivalent per gram of dry extract (mg EAG / g ES) optical density measurement was performed at a wavelength of $765 \mathrm{~nm}$.

The results obtained from whole oat and oat bran extracts (PWO, BWO, POB, $\mathrm{BOB}$ ) analyzed reveal that $\mathrm{BOB}$ is richer in total polyphenols with a content of $0.216 \pm 0.0117$ (mg EAG / g ES), than POB with a content of $0.203 \pm 0.005$ (mg EAG / g ES), and PWO is richer in total phenolic compounds $0.205 \pm 0.013$ (mg EAG / g ES) than BWO $0.107 \pm 0.014$ (mg EAG / g ES) .(Table 2). Flavonoids are the most important polyphenolic, the flavonoid content of each extract was calculated from the calibration curve $\mathrm{y}=4.6153 \mathrm{x}-0.0118$, where $\mathrm{y}$ is the absorbance and $\mathrm{x}$ the concentration and expressed in milligrams equivalent of quercetin per gram of dry extract (mg EQ / g ES, Optical density measurement was performed at wavelength of $510 \mathrm{~nm}$. The results obtained from the oat extracts (PWO ,BWO,POB,BOB) analyzed reveal that the PWO contains a flavonoid content of $0.192 \pm 0.371(\mathrm{mg}$ EQ/gES) higher than that of BWO $0.093 \pm$ 0.006 ( $\mathrm{mg} \mathrm{EQ} / \mathrm{gES})$, and $\mathrm{BOB}$ is rich in flavonoids of $0.201 \pm 0.025$ (mg EQ/g ES) when supplied to the POB $0.071 \pm 0.020$ (mg EQ/gES) (Table 2). The results obtained for the determination of total polyphenols and flavonoids reveal that the extracts of whole oats and oat bran of the two varieties (prevision and black) contain high levels of total polyphenols and flavonoids.

The polyphenol content of the different varieties of oats is higher due to their flavonoid content. the rate of phenolic content of whole oat varies from 0.35-0.90 $\mathrm{mg} / \mathrm{g}$. according to a study made by[16]. By comparing our results obtained by intake with those of [17], that the total phenolic content varies from one variety to another, These differences may be due to genetic differences, methods of test, oat varieties used, degree of ripeness, extraction solvents, and environmental conditions. It has been shown that most of the ingredients including dietary fiber, minerals, tocopherols and phenolic compounds are concentrated on the bran layer, while most starch is mainly distributed on the endosperm of the kernels [17]. From the final results obtained and the differences observed in phenolic compounds and flavonoids for the two varieties of oats cultivated in Sidi Bel Abbes and Tiaret, suggest that there may be many factors that influence the content of whole grain phenolic compounds, including variety (genetics) and differences in agro-climatic.

Heat treatments are used in the case of grains treated before consumption (drying, steaming and boiling water), these processes have an impact on the content of phenolic compounds. Although these processes should decrease the content of phenolic compounds, they can have a

Samira MEZIANI, Noreddine MENADI, Hayet Mehida, Soheila OUGAD, Souad SAIDANI, Lahouaria LABGA, Evaluation of phenolic compound and antioxidant capacity of two varieties of oats (Avena Sativa L): bran oats and whole grain (black and prevision oats), Food and Environment Safety, Volume XX, Issue 1 - 2021, pag. 61 - 67 
favorable effect on the bioaccessibility and bioavailability of these elements, the majority of these compounds are closely related to the cellulosic matrix.

Table 2

Dry extract yield in \%,total phenolic content in mg EAG /g, flaonoids in mgEQ /g.

\begin{tabular}{|c|c|c|c|}
\hline Parameters & Dry extract yield \% & $\begin{array}{c}\text { Total phenolic } \\
\text { Varieties }\end{array}$ & $\begin{array}{c}\text { Flavonoids content } \\
(\mathrm{mgEQ} / \mathrm{g})\end{array}$ \\
\hline PWO & 9.5 & $0.205 \pm 0,013$ & $0.192 \pm 0.371$ \\
\hline BWO & 7.9 & $0.107 \pm 0,014$ & $0.093 \pm 0.006$ \\
\hline POB & 11.4 & $0.203 \pm 0,005$ & $0.071 \pm 0.020$ \\
\hline BOB & 4.2 & $0.216 \pm 0,0117$ & $0.201 \pm 0.025$ \\
\hline
\end{tabular}

$P W O$ : prevision whole oat

$B W O$ : black wholeoat

$P O B$ : Prevision oat bran

$B O B$ : Black oat bran

\subsection{Anti-free radical activity with DPPH}

The results of the anti-free radical activity or the inhibition of free radicals are expressed as a percentage of inhibition (I\%) estimated according to the equation below

I $(\%)=($ Abs (control)- Abs (ext) $/$ Abs control $* 100$ I \%: Percentage of anti-free radical activity

Abs Control :Absorbance of the DPPH solution at Time 0 Abs ext: abosrobance of the extract .

The IC50 $\quad(50 \%$ inhibitory concentration), also called EC50 (Efficient concentration 50), is the concentration of the sample tested necessary to reduce $50 \%$ of the DPPH radical.

The IC50s are calculated graphically by percentages of inhibition as a function of the different concentrations of the extracts tested [19], a low value of the IC50 indicates a strong antioxidant activity. By comparing the results of IC 50 of the varieties of whole oats and oat bran with that of ascorbic acid (reference antioxidant) we see that the IC 50 of the varieties of whole oats and oat bran are higher than that of ascorbic acid With values of $11 \mathrm{mg} / \mathrm{ml}$ for BWO and 6.37 $\mathrm{mg} / \mathrm{ml}$ for PWO, $6.15 \mathrm{mg} / \mathrm{ml}$ for POB and $2.95 \mathrm{mg} / \mathrm{ml}$ for BOB by intake at $0.0295 \mathrm{mg} / \mathrm{ml}$ for ascorbic acid.

So the antioxidant capacity of ascorbic acid is higher than that of whole oat and oat bran varieties, because the antioxidant capacity of a compound is higher when its IC50 value is small. Then we see that the BOB has a higher antioxidant power when compared to the POB and when compared to the BWO and PWO.

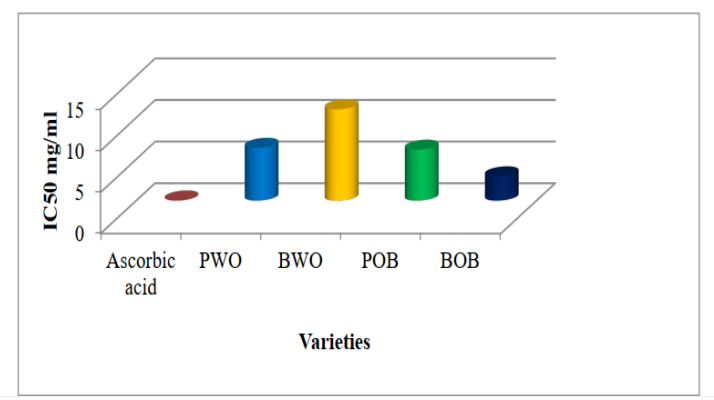

Fig 1: Histogram of the values of the inhibitory concentrations 50 of the different varieties in $\mathrm{mg} / \mathrm{ml}$

Samira MEZIANI, Noreddine MENADI, Hayet Mehida, Soheila OUGAD, Souad SAIDANI, Lahouaria LABGA, Evaluation of phenolic compound and antioxidant capacity of two varieties of oats (Avena Sativa L): bran oats and whole grain (black and prevision oats), Food and Environment Safety, Volume XX, Issue 1-2021, pag. 61 - 6765 
The results observed for whole oats and its by-products (oat bran) showed a high antioxidant capacity compared to the results found by [17]. The extraction procedures, the agronomic conditions or of geographical origin can explain this increase. In addition, the antioxidant activity is a powerful scavenger of free radicals which can be exerted by modulating the defenses by the action of phenolic compounds according to a study carried out by [18].

\section{Conclusion}

Oat grains are a good source of protein, fiber, vitamins and certain natural compounds with important phytochemical properties such as (polyphenols and flavonoids). The regular consumption of oats in whole grain and the by-product of this species (oat bran) would be particularly beneficial in reducing the risk of cardiovascular disease has many medicinal properties and therapeutic since it is able to regulate the metabolism of carbohydrates in people with diabetes, and thus facilitating the intestinal transit. In this study, black oat bran is considered to be an important source of phenolic compounds. The varietals differences may be due to genetic differences, methods of test, oat varieties used, degree of ripeness, extraction solvents, and environmental conditions. This work deserved to be depth studied, particularly with regard to their effects on human health.

\section{Acknowledgments}

The authors acknowledge the University of Sidi Bel Abbes, Biology Department at Sidi Bel Abbes for the financial support of this research. SM wrote the manuscript and supervised in final reviewer the manuscript; NM and SO participated in the experiment of this study; HM supervised data analysis; SS and LL for vegetal materials and designed for English grammar correction.

\section{References}

[1]. HANSEN JM., The earliest seed remains from Greece: Palaeolithic through Neolithic at Franchthi Cave.Berichte der deutschen botanischen Gesellshaft, 91,39-6, (1978).

[2]. GRAY DA., CLARKE MJ., BAUX C., BUNTING JP., SALTER AM, Antioxidant Activity of Oat Extracts added to Human LDL Particles and in Free Radical Trapping Assays. J. Cereal Sci;36(2):209-18. doi:10.1006/jcrs.2001.0456, (2002).

[3]. AHMAD A., ANJUM FM., ZAHOOR T., NAWAZ H., AHMED Z., Extraction and characterization of oat $\beta$-glucan for industrial use. IntJ Biol Macromo; 46: 304-309, (2010). [4]. DANIELS DG, MARTIN HR, Antioxidants in oats: monoesters of caffeic and ferulic acids. J Sci Food Agric; 18: 589-595, (1967)

[5]. HEAD DS., CENKOWSKI S., ARNTFIELD S., HENDERSON K, Oatmeal superheated steam treatment. LWT, Food Sci Technology; 43: 690694, (2010)

[6]. ZWIER, P., K.OATS.IN: WRIGLEY C., CORKED H., AND WALKER C., (eds) Encyclopedia of Grain Science. Oxford: Elsevier. International Federation of Societies of Cosmetic Chemists, (2004)

[7]. PETERSON DM., Oat antioxidants. J. Cereal Sci. 33: 115-129, (2001)

[8]. RASANE P., JHA A., SABIKHI L., KUMAR A., UNNIKRISHNAN VS, Nutritional advantages of oats and opportunities for its processing as value added foods - A review. J. Food Sci. Technol, 52 (2):662-75. doi:10.1007/s13197-013-1072-1, (2015)

[9]. CZERWINSKI J., BARTNIKOWSKA E., LEONTOWICZ H., LANGE E., LEONTOWICZ M., KATRICH E., TRAKHTENBERG S., AND GORINSTEIN S, Oat (Avena sativa L.) and amaranth (Amaranthus hypochondriacus) meals positively affect plasma lipid profile in rats fed cholesterol containing diets. Journal of Nutritional Biochemistry, 15, 622-629, (2004)

[10]. MARLETT JA, Comparisons of dietary fiber and selected nutrient compositions of oat and other grain fractions. In: Wood PJ (ed) Oat bran, (1993)

[11]. BOIZOT N., AND CHARPENTIER JP, Rapid method for evaluating the content of phenolic compounds in the organs of a foliage tree. The INRA techniques book. pp 79-82. (2006) [12]. PASCAL RIBÉREAU-GAYON, Phenolic compounds in plants (1968) 
[13]. ZHISHEN J, MENGCHENG T AND JIANMING $\mathrm{W}$, The determination of flavonoid contents in mulberry and their scavenging effects on superoxide radicals. Food Chemistry, 64, 555559, (1999)

[14]. MANSOURI A., GUENDEZ E., KOKKALOU E. AND KEFALAS P, Phenolic profile and antioxidant activity of Algerian ripe date palm (Phoenix dactylifera).Food.Chem.89:411-420, (2005) [15]. SÁNCHEZ-MORENO JOSÉ A., LARRAURI FULGENCIO SAURA-CALIXTO, journal of the science of food and agriculture, (1999).

[16]. BELOBRAJDIC ET BIRD, most abundant phytomicronutrients according to the cereal considered, (2013)
[17]. CHAO CHEN., LI WANG., REN WANG., XIAOHU LU.,OYONGFU LI., JUAN LI., YANAN LI., ZHENGXING CHE, (Phenolic contents, cellular antioxidant activity and antiproliferative capacity of different varieties of oats, (2018).

[18]. MADHUJITH H., ET SHAHIDI F., Antioxidant and anti-oliferative property of certain cultivars of barley (Hordeum vulgarae L.) and their potential for inhibiting the oxidation of low density lipoprotein (LDL) cholesterol, J. Agric. Food. Chem. 55 (13): 5018-5024, (2007).

[19]. MOLYNEUX P.,The use of the stable free radical diphenylpicrylhydrazyl (DPPH) for estimating antioxidant activity, (2004) 